\title{
Temporal Dynamics of Jellyfish Pelagia noctiluca Stranded on the Mediterranean Coast of Morocco
}

\author{
Bilal Mghili ${ }^{1, *}\left(\mathbb{D}\right.$, Mohamed Analla $^{1}$, Mustapha Aksissou $^{1}$ \\ ${ }^{1}$ Abdelmalek Essaadi University, Faculty of sciences, Department of Biology, Tetouan, Morocco
}

\author{
Article History \\ Received 13 August 2020 \\ Accepted 08 December 2020 \\ First Online 09 December 2020 \\ Corresponding Author \\ Tel.: +212610103615 \\ E-mail: b.mghili@uae.ac.ma
}

\section{Keywords}

Populations dynamics

Mauve stinger

Jellyfish

Mediterranean Sea

\begin{abstract}
Seasonal dynamics of the scyphomedusa Pelagia noctiluca were studied along with their relation to certain environmental factors between the study period that extends from January 2018 to December 2019. During 2018, stranded individuals of $P$. noctiluca appeared throughout this year, but their high frequency was reported in the summer . While in contrast, $P$. noctiluca in 2019 was reported in a very low number only during the winter season and had not been detected in the other seasons of this year. The overall results revealed that the inter-annual variations in the abundance of jellyfish were not significantly $(\mathrm{P}<0.05)$ correlated with water temperature, relative humidity and atmospheric pressure. Our results showed easterly winds as a significant predictor of $P$. noctiluca strandings. The bell diameters of examined jellyfish ranged from 30 to $130 \mathrm{~mm}$, with mean of $72 \mathrm{~mm}$. Stranded mature jellyfish individuals as well as young ones were recorded throughout the year 2018. The size distribution indicated that $P$. noctiluca can reproduce all around the year, with its more intense activityduring the spring. The continuing presence of $P$. noctiluca in the Moroccan Mediterranean makes it necessary to set effective strategies in order to prevent and minimize their impact on economic activities.
\end{abstract}

\section{Introduction}

Pelagia noctiluca (Scyphozoa, Semaeostomeae, Pelagiidae) is a pelagic species of jellyfish that have purple to pink color with brown, blue, and magenta pigments, and a bell of 3 to $12 \mathrm{~cm}$ in diameter. It is generally known as 'a purple stinger'. This jellyfish is a holoplanktonic species (without a benthic polyp stage). This characteristic permits individuals of $P$. noctiluca to inhabit coastal and oceanic ecosystems (Canepa et al., 2014). It is widely distributed in the Mediterranean Sea, the Atlantic Ocean, and the Pacific Ocean. Pelagia noctiluca outbreaks are described negatively in the scientific literature, because this species can cause damage to various economic activities, such as tourism, fisheries, and aquaculture (Purcell et al., 2007; Canepa et al., 2014). In addition, $P$. noctiluca is an opportunistic predator that feeds on multiple prey, including zooplankton, icthioplankton, fish eggs and larvae (Rosa et al., 2013; Tilves et al., 2016).

In the Mediterranean Sea, $P$. noctiluca is a most abundant jellyfish species, which shows an important inter-annual fluctuation (Goy et al., 1989). The presence of $P$. noctiluca in the Mediterranean has been documented in 1785 (Spallanzani, 1799), but the abundance of this species has become more frequent since 1999 with spatial increases and dramatic temporal changes in their distribution (Brotz \& Pauly, 2012). Indeed, the study of its density during the last century in the Mediterranean shows that the proliferation of this species presents a periodicity of about 12 years (Goy et al., 1989). The chronology of recent outbreaks of $P$. noctiluca does not correspond to the seasonal cycle previously described (Daly Yahia et al., 2010). In the absence of long-term data on jellyfish bloom, it is not possible to establish whether the jellyfish population 
has effectively increased (Condon et al., 2012). Therefore, monitoring jellyfish abundance, distribution, and population dynamics have become a priority in all oceans (Sabatés et al., 2010). Within this context, many surveillance programs have been conducted to assess jellyfish species diversity and abundances such as visual observation from ships of opportunity (Doyle et al., 2007), shoreline strandings (Houghton et al., 2007), and aerial surveys (Houghton et al., 2006). Among these methods, stranding monitoring networks are low-cost methods and they are commonly used to monitor the spatial and temporal distribution of jellyfish (Canepa et al., 2014).

In the Tetouan Sea (Western Mediterranean), the scyphomedusa $P$. noctiluca is the most abundant jellyfish species and its abundance has increased in recent years (Aouititen et al., 2019). This species has been present almost continuously in the Moroccan Mediterranean and many thousands are often seen stranded on the beaches. In response to both the lack of knowledge about this species in the Mediterranean Sea and also its high abundances observed in the Tetouan Sea, we have launched a field study to examine the seasonal variation in the abundance and size distribution of $P$. noctiluca. We have evaluated some environmental factors that may stimulate the proliferation and stranding of $P$. noctiluca along the Moroccan Mediterranean coast.

\section{Materials and Methods}

From January 2018 till December 2019, stranded individuals of Pelagia noctiluca were studied in the Mediterranean coast of Morocco, the Western Mediterranean Basin. Jellyfish were found stranded at

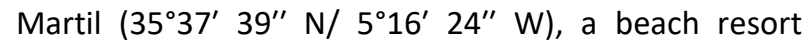
located at the province of M'diq-Fnideq, North-East of Morocco, in the Alboran Sea (Figure 1). This area is characterized by high planktonic production due to changes in the hydrological structure, which is an area of passage of many migratory animals between the Mediterranean and the Atlantic and is an important area for tourism, fishing and industry.

Data on stranded jellyfish was collected according to the method described by Doyle et al. (2007). The sampling method included a walk along a distance of one kilometer of the beach to record the presence or absence of stranded $P$. noctiluca individuals. During the first sampling day, start and end positions of the transect in the study area were recorded using GPS.

Individuals of $P$. noctiluca were found stranded between high and low tide. Stranded specimens had a hemispherical, transparent umbrella. Jellyfish were purple to pink in color with brown, blue and magenta pigments. The abundance/density of $P$. noctiluca is given as Ind. $\mathrm{Km}^{-1}$.

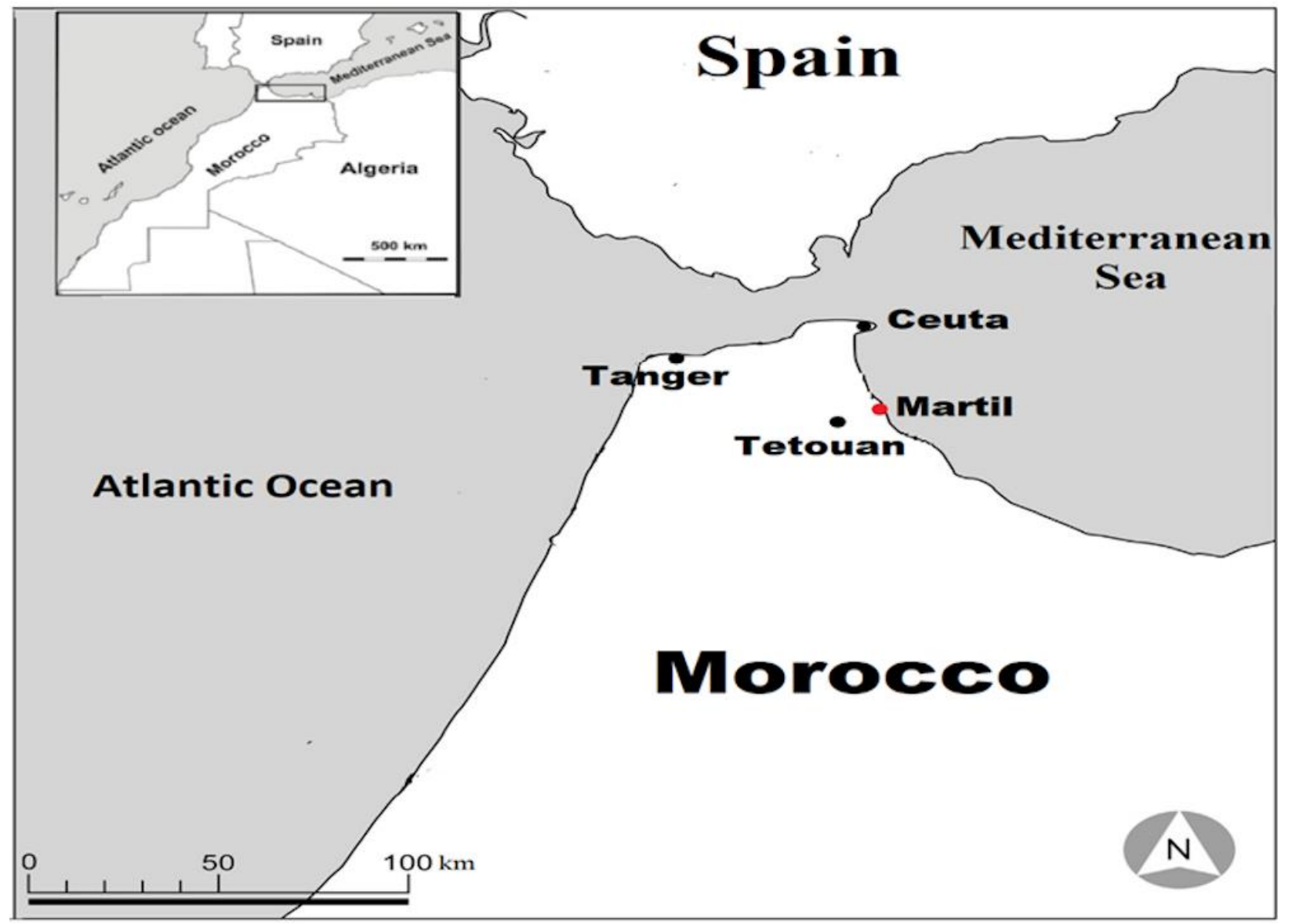

Figure 1. The location of Pelagia noctiluca stranding in north-western Morocco ( $\left.35^{\circ} 37^{\prime} 39^{\prime \prime} \mathrm{N} / 5^{\circ} 16^{\prime} 24^{\prime \prime} \mathrm{W}\right)$. 
The bell diameters of 1446 P. noctiluca individuals were measured to the nearest $\mathrm{mm}$ using ruler. Each individual was assigned to size classes, varying from a minimum of $30-40 \mathrm{~mm}$ to a maximum of $120-130 \mathrm{~mm}$. Pelagia noctiluca has been classified into five size classes using measurements of bell diameter: $<1.0 \mathrm{~cm} ; 1.0<3.5$ $\mathrm{cm}$ (Immature medusa); $3.5<6.0 \mathrm{~cm}$ (Conditionally mature); $6.0<8.5 \mathrm{~cm}$ (Mature); $>8.5 \mathrm{~cm}$ (Malej \& Malej, 2004).

The time and date of the survey were recorded at each location. The intensity and the direction of the wind, relative humidity, and atmospheric pressure were obtained from the Tetouan climate station. The temperature of the water was obtained by the fish farm Aqua M'diq (Tetouan). A monthly average of water temperature was used for correlation analysis with jellyfish abundance.

The association of each environmental factor (i.e., relative humidity, atmospheric pressure, surface water temperature, and wind intensity) to the abundance variations of $P$. noctiluca was evaluated using Pearson's correlation. In order to determine if the presence of stranded $P$. noctiluca was influenced by wind direction, the ANOVA test was also utilized. The data were analyzed using SPSS software version 20 (IBM, 2011).

\section{Results}

A total of 6409 specimens of Pelagia noctiluca were stranded between January 2018 and December
2019 in the study area. Figure 2 shows a big stranding of $P$. noctiluca on Martil beach in December 2018. Pelagia noctiluca was observed in almost all months of 2018 and its density fluctuated during this year and tended to increase during the summer season (Figure 3). In 2018, the first stranding was observed on 6 January $(25$ Ind. $\left.\mathrm{Km}^{-1}\right)$. One month later, 35 individuals were stranded. This jellyfish disappeared during the spring (May-June) to reappear again in early summer reaching its highest abundance in August. Generally, $P$. noctiluca was found throughout this month, but very big strandings occurred on the period from 1 till 12 August, namely 5257 individuals were stranded per km. During this two week period, the wind was blowing strongly from the East with speed up to $21.8 \mathrm{~km} \cdot \mathrm{h}^{-1}$. In the following days, there were less $P$. noctiluca stranded, but very high numbers of individuals were observed offshore. From September to November, individuals of $P$. noctiluca also appeared at high densities: six strandings were observed on Martil beach during these months (471 Ind. $\mathrm{Km}^{-1}$ ). On 30 December, $P$. noctiluca individuals were still very abundant in the study area (352 Ind. $\mathrm{Km}^{-1}$ ).

In 2019, $P$. noctiluca was observed for the first time on 12 January with 23 individuals per Km (Figure 4), becoming highly dense in the following day (118 Ind. $\mathrm{Km}^{-1}$ ). On 25 January, $P$. noctiluca was also found stranded (105 Ind. $\mathrm{Km}^{-1}$ ). The density decreased from February to March and and no strandings were found from May to December 2019.

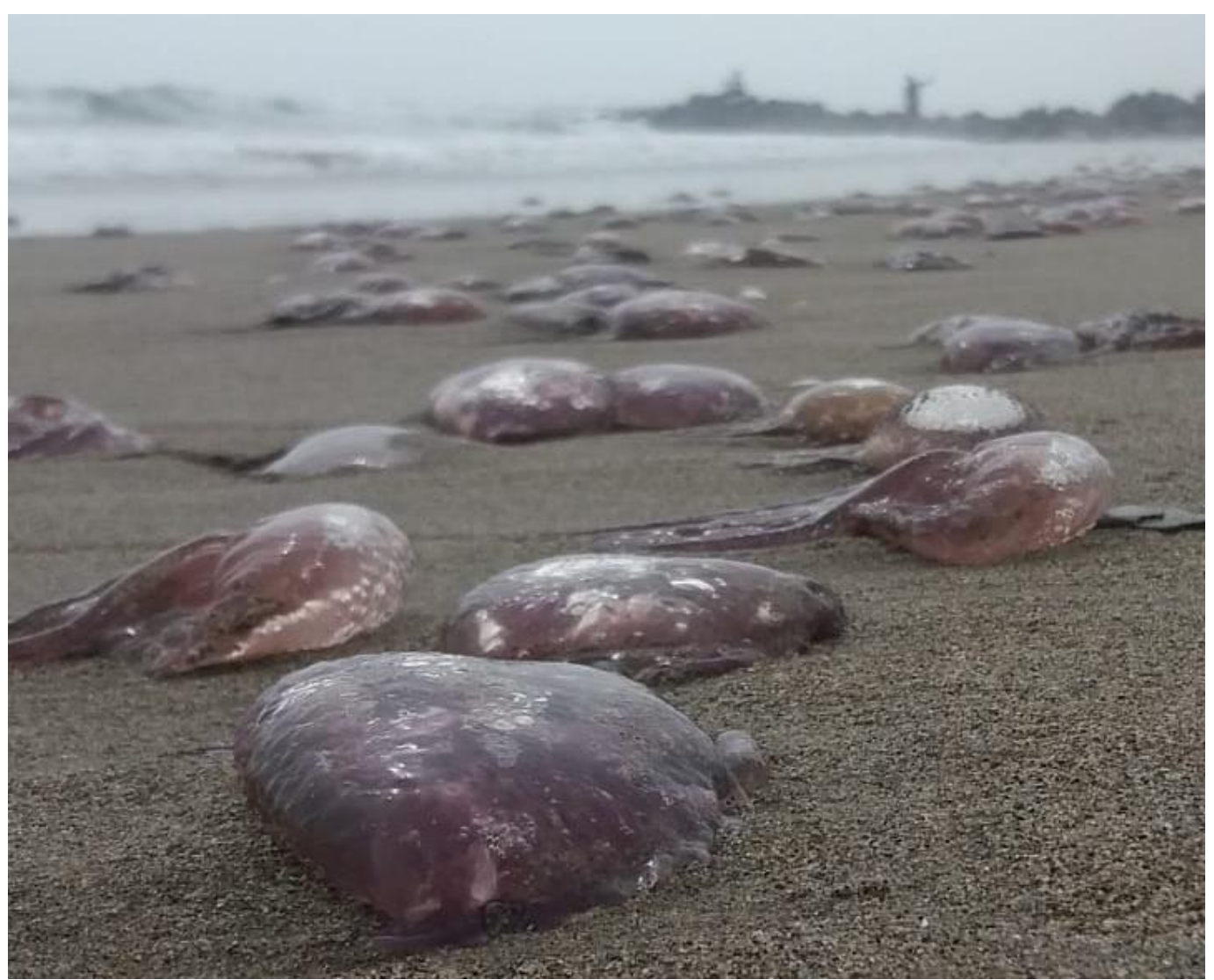

Figure 2. Abundant stranding of Pelagia noctiluca on Martil beach, during December, 2018. 
The bell diameter of examined $P$. noctiluca individuals ranged from 30 to $130 \mathrm{~mm}$, with mean of 72 $\mathrm{mm}(\mathrm{SD}=19.92$ ) (Figure 5). Medium size individuals of 50-70 $\mathrm{mm}$ bell diameter were recorded in all seasons. Maximum size of bell diameter of $130 \mathrm{~mm}$ was observed in December, 2018 and January, 2019. The population observed during the winter of 2018 was mainly composed by adult individuals with bell diameter larger than $70 \mathrm{~mm}$, unlike summer population that was mostly composed of small specimens with mean bell diameter of $52.97 \mathrm{~mm}$ (SD=52.95) (Figure 6).

Water temperature showed similar temporal variations in both years of the study. The minimum daily average of surface temperature was $15^{\circ} \mathrm{C}$ in 2018 and $14^{\circ} \mathrm{C}$ in 2019 , while the maximum daily average of surface water temperature was $23^{\circ} \mathrm{C}$ in the both years 2018 and 2019. Correlation analyses between the abundance of stranded jellyfish and monthly water temperature average in each year was never significant in 2018 nor in 2019: $r=0.45 \quad(P>0.05)$ and $r=-0.29$ ( $P>0.05)$, respectively. Relative humidity did not change between these two years, and average values were always above $55 \%$. Atmospheric pressure varied from 1006 to $1033 \mathrm{hPa}$. No significant correlation between the density of $P$. noctiluca and relative humidity and atmospheric pressure was observed. However, the east wind was significantly $(P<0.05)$ associated with jellyfish stranding on the days it occurred.

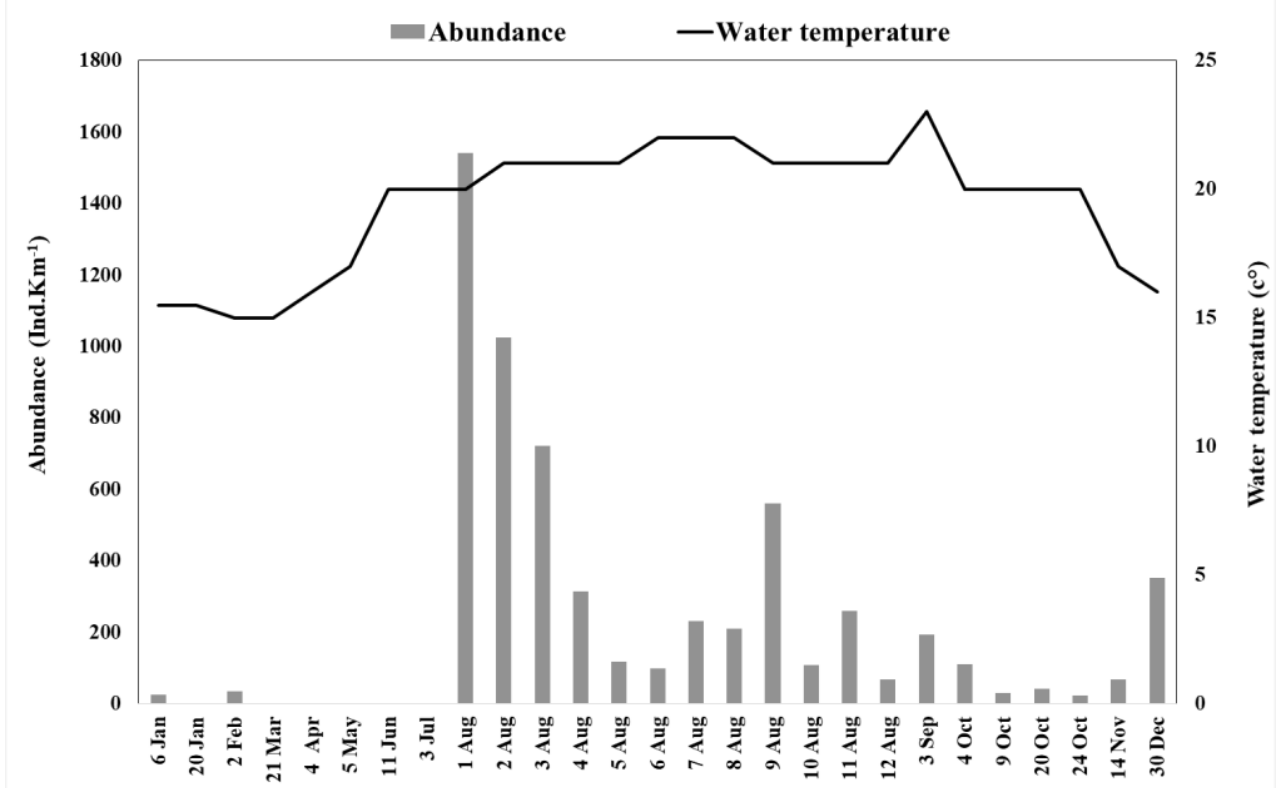

Figure 3. Temporal variation of water temperature and abundance of Pelagia noctiluca stranded on Martil beach, from January to December 2018.

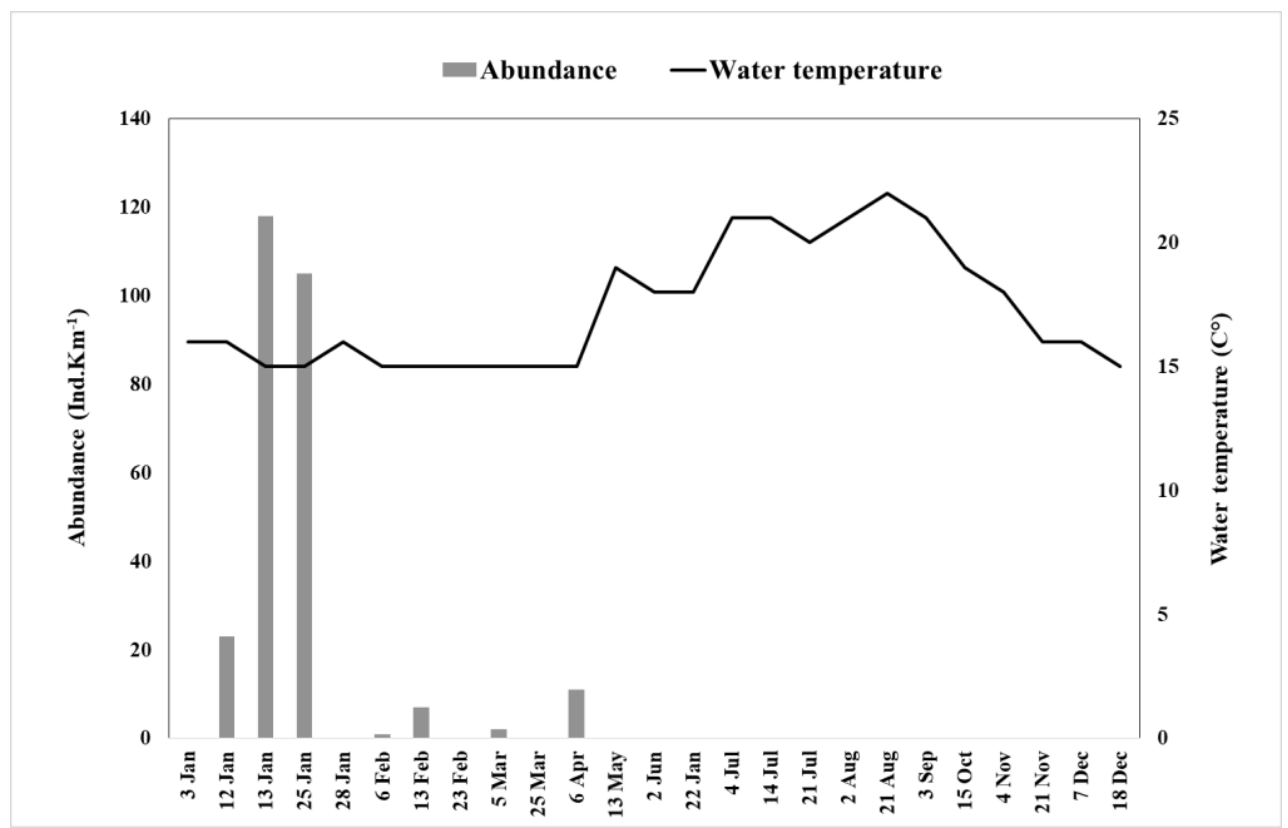

Figure 4. Abundance of Pelagia noctiluca and water temperature co-variation in the Martil beach from January to December 2019. 


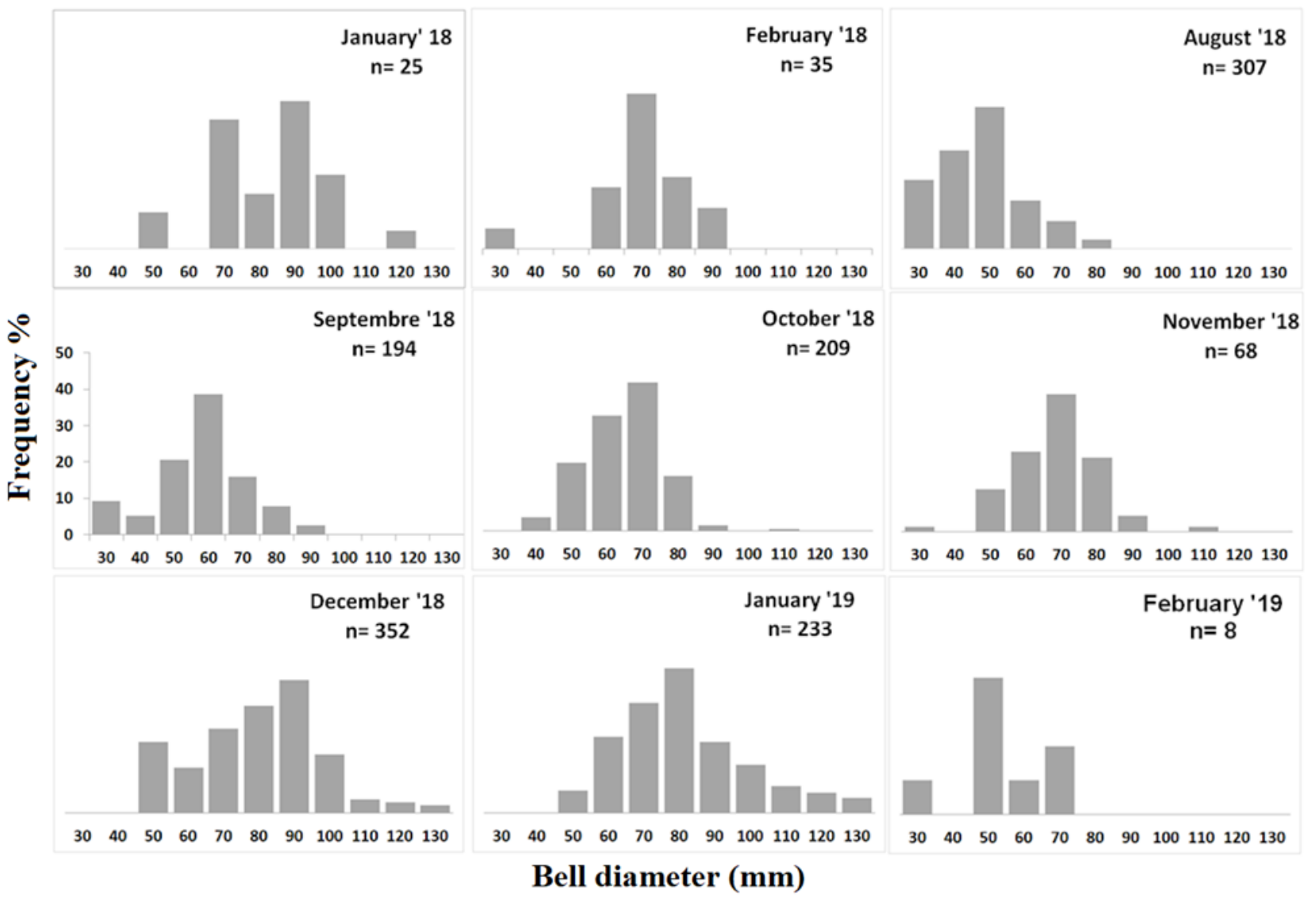

Figure 5. Bell diameter frequency distibution of Pelagia noctiluca during the study period from January 2018 to December 2019.

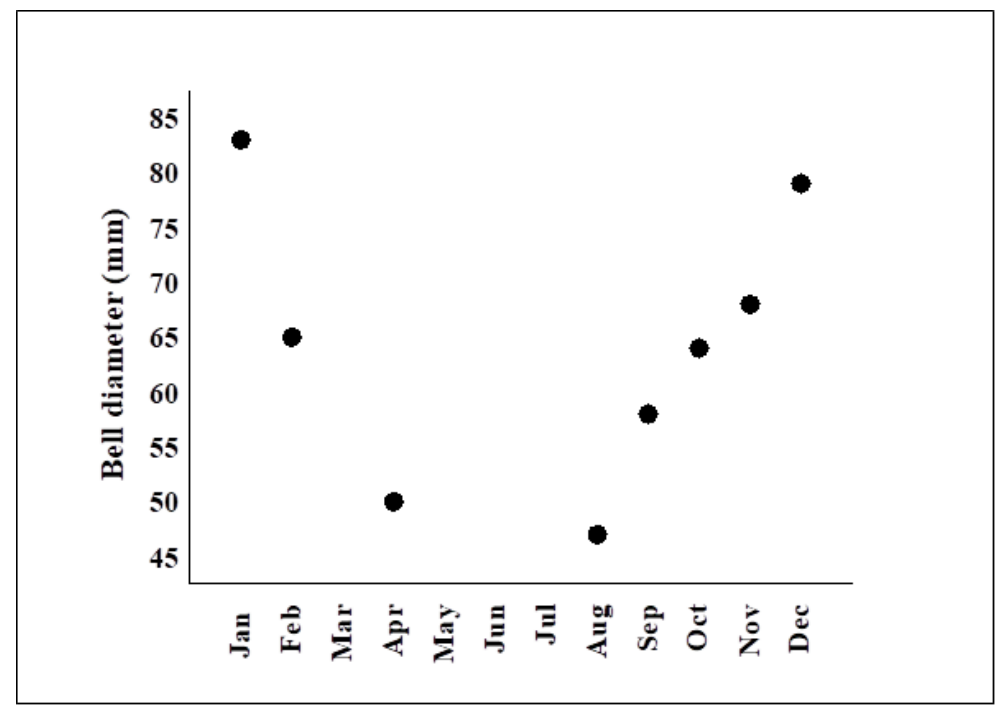

Figure 6. Temporal change in mean bell diameter of Pelagia noctiluca in 2018.

\section{Discussion}

Pelagia noctiluca is one of the most important species of Scyphozoa that blooms along the Moroccan Mediterranean. During two years of study, $P$. noctiluca showed a large seasonal variation. Higher densities occurred in 2018 than in 2019. In 2018, P. noctiluca was observed over eight months, but the repartition of this species seems to be higher in the summer-autumn period. In 2019, P. noctiluca was present from January to March, while in the summer and autumn seasons, no jellyfish stranding was observed, which suggests that $P$. noctiluca was probably absent or very rare during these two seasons of the year. A comparison of our data with the results of beach stranding in the same area by Aouititen et al. (2019) indicates that $P$. noctiluca stranding is more abundant during the summer and autumn. Data on $P$. noctiluca stranded on the Mediterranean beaches of Spain were collected from May to September 2007-2010 (Canepa et al., 2014). 
Canepa et al. (2014) reported that this species is most abundant along the Mediterranean of Spain during summer and autumn. Conversely, in the Strait of Messina this jellyfish is more frequent during winter (Rosa et al., 2013), while in the Tunisian coasts, this species is the most abundant, mainly in winter and autumn (Aissi et al., 2014). Along the French Mediterranean coast, high abundances of $P$. noctiluca are maintained throughout the winter and the blooming season terminates in summer (Hecq et al., 2009).

The seasonal occurrence pattern of $P$. noctiluca was different between the two years of the study. Although, inter-annual variability in the abundance of jellyfish has been observed elsewhere. For example, Purcell et al. (2000) reported that the abundance of Aurelia labiata in Alaska changed between years. Our results showed that most of the correlations of $P$. noctiluca abundance with abiotic variables were not significant. With just two years of study, it is difficult to determine conclusions about the factors causing interannual variations in the abundance of $P$. noctiluca, but several factors may be involved. Goy et al. (1989) suggested that late spring conditions favor the bloom of this species during the blooming summer. In particular, temperatures above $10^{\circ} \mathrm{C}$ in winter and below $27^{\circ} \mathrm{C}$ in summer, along with salinities of 35-38 are better conditions for the appearance of $P$. noctiluca (Goy et al., 1989; Molinero et al., 2005). Some studies suggest that temperature alters the activity (pulsation rate) of this jellyfish: lower temperatures induce slower swimming and decreased foraging ability (Rottini-Sandrini \& Avian, 1989). Concurrently, the temporal dynamics of $P$. noctiluca appears to be controlled by local factors that favor the retention of this jellyfish, thus raising its local abundance and survival time (Rosa et al., 2013).

In addition, physical forcing (wind direction and intensity and tidal effects) has been the cause of aggregations of $P$. noctiluca in both coastal and offshore waters (Berline et al., 2013). Our study of the stranding of $P$. noctiluca in the Tetouan Sea revealed that the stranding events were associated with East winds. Indeed, further sampling will be necessary to establish the causes behind the blooming of this species, along the Moroccan Mediterranean. Doyle et al. (2007) suggested that the jellyfish stranding monitoring method should be applied with other sampling techniques that can assess the presence of gelatinous organisms in column water.

The combination of our results with those of Aouititen et al. (2019) shows that $P$. noctiluca remained abundant for most years from 2011 to 2019, except in 2013. Consequently, the period of abundance studied along the Moroccan Mediterranean does not correspond to the model of Goy et al. (1989), which proposes a 12-year cycle, divided into 5 years with a high probability of occurrence, 5 years with a low probability, and 2 years with an average probability. This model began to change in late 1990, where blooms occurred almost annually (Daly Yahia et al., 2010; Bernard et al.,
2011; Brotz \& Pauly, 2012), while in the Aegean Sea, the model was similar to the 12-year cycle periodicity (Daly Yahia et al., 2010).

In the Mediterranean Sea, though the breeding data for $P$. noctiluca were available, but the spawning period of this species was not clearly defined. Haeckel (1880) remarked that autumn and winter was the better breeding period for $P$. noctiluca in the waters of Sicily. Lo Bianco (1909) and Rottini-Sandrini and Avian (1983) described a longer reproduction period for $P$. noctiluca, with more intense activity in autumn. Along the Mediterranean of French, $P$. noctiluca reproduces during summer-autumn (Morand et al., 1992); whereas in the Atlantic these jellyfish reproduced in autumn (Kramp, 1924). However, both Lo Bianco (1909) and Kramp (1924) suggested that these jellyfish had a longer reproductive period in the Mediterranean Sea than in the Atlantic Ocean. Goy et al. (1989) reported intense reproduction from May to August. In the Strait of Messina, Rosa et al. (2013) suggested that $P$. noctiluca reproduces throughout the year, with maximum activity in late autumn-winter, while Milisenda et al. (2016) reported two seasonal peaks (spring, autumn). Analysis of biometric data of $P$. noctiluca stranded along the Moroccan Mediterranean suggests that this jellyfish reproduces throughout the year, with a more intense activity during spring.

It seems that $P$. noctiluca can potentially reproduce all over the year. However, its reproductive success is directly related to environmental factors (RottiniSandrini \& Avian, 1991).

\section{Conclusions}

The continued stranding of Pelagia noctiluca is indicating that the Moroccan Mediterranean Sea represents an important area of proliferation and reproduction of this species. A jellyfish regional monitoring network should be used along the Moroccan Mediterranean in order to observe and investigate temporal and spatial distribution of $P$. noctiluca, its fluctuation, as well as the dominant hydrodynamic conditions, in order to predict the conditions favoring its outbreak in the Moroccan Mediterranean.

\section{References}

Aissi, M., Touzri, C., Gueroun, S.K., Daly Yahia, O.K., \& Daly Yahia, M.N. (2014). Persistent occurrence and life cycle of Pelagia noctiluca in the channel of Bizerte (Northern Tunisia). Ecology, Environment and Conservation, 20 (4), 1453-1460.

Aouititen, M., Bekkali, R., Nachit, D., Luan, X., \& Mrhraoui, M. (2019). Predicting Jellyfish Strandings in the Moroccan North-West Mediterranean Coastline. European Scientific Journal, 15, 72-84. https://doi.org/10.19044/esj.2019.v15n2p72

Berline, L., Zakardjian, B., Molcard, A., Ourmiéres, Y., \& Guihou, K. (2013). Modeling jellyfish Pelagia noctiluca transport and stranding in the Ligurian Sea. Marine 
Pollution Bulletin, 70, 90-99.

http://dx.doi.org/10.1016/j.marpolbul.2013.02.016

Bernard, P.L., Berline, L., \& Gorsky, G. (2011). Long term (19812008) monitoring of the jellyfish Pelagia noctiluca (Cnidaria, Scyphozoa) on Mediterranean Coasts (Principality of Monaco and French Riviera). Journal of Oceanography, Research and Data, 4, 1-10.

Brotz, L.D., \& Pauly, D. (2012). Jellyfish populations in the Mediterranean Sea. Acta Adriatica, 53, 211-230. https://hrcak.srce.hr/94422

Canepa, A., Fuentes, V.L., Sabatés, A., Piraino, S., Boero, F., \& Gili, J.M. (2014). Pelagia noctiluca in the Mediterranean Sea. In K.A. Pitt \& C.H. Lucas (Eds), Jellyfish blooms SE11. Springer Netherlands (2nd ed., pp. 237-266). https://doi.org/10.1007/978-94-007-7015-7_1

Condon, R.H., Graham, W.M., Duarte, C.M., Pitt, K.A., Lucas, C.H., Haddock, H.D., Sutherland, K.R., Robinson, K.L., Dawson, M.N., Decker, M.B., Mills, C.E., Purcell, J.E., Malej, A., Mianzan, H., Uye, S., Gelcich, S., \& Madin, L.P. (2012). Questioning the rise of gelatinous zooplankton in the world's oceans. Bioscience, 62(2), 160-169. https://doi.org/10.1525/bio.2012.62.2.9

Daly Yahia, M.N., Batistic, M., Lucić, D., Fernández de Puelles, M.L., Licandro, P., Malej, A., Molinero, J.C., SiokouFrangou, I., Zervoudaki, S., Prieto, L., Goy, J., \& Daly Yahia-Kéfi., O. (2010). Are the outbreaks of Pelagia noctiluca (Forsskål, 1775) more frequent in the Mediterranean basin? In A. Gislason \& G. Gorsky (Eds), Proceedings of the joint ICES/CIESM workshop to compare zooplankton ecology and methodologies between the Mediterranean and the North Atlantic (WKZEM): ICES Cooperative Research Report, 300. Copenhagen, Denmark, p. 8-14.

Doyle, T.K., Houghton, J.D.R., Buckley, S.M., Hays, G.C., \& Davenport, J. (2007). The broad-scale distribution of five jellyfish species across a temperate coastal environment. Hydrobiologia, 579, 29-39. http://doi.org/10.1007/s10750-006-0362-2

Goy, J., Morand, P., \& Etienne, M. (1989). Long-term fluctuations of Pelagia noctiluca (Cnidaria, Scyphomedusa) in the western Mediterranean Sea. Prediction by climatic variables. Deep Sea Research, 36(2), 269-279. https://doi.org/10.1016/0198-0149(89)90138-6

Haeckel, E. (1880). Das system der medusen [The medusae system]. Monographie der Medusen. Gustav Fischer Verlag, Jena, pp. 499-510.

Hecq, J.H., Goffart, A., Collignon, A., Plazza, S., Defreygne, P.S., \& Lejeune, P. (2009). La variabilité de la méduse Pelagia noctiluca (Forskal, 1775) en Baie de Calvi (Corse) en relation avec l'environnement [The variability of the jellyfish Pelagia noctiluca (Forskal, 1775) in the Bay of Calvi (Corsica) in relation to the environment]. Rapport pour Agence de l'Eau Rhône Méditerranée et Corse, 48 pp.

Houghton, J.D.R., Doyle, T.K., Davenport, J., \& Hays, G.C. (2006). Developing simple, rapid method for identifying and monitoring jellyfish aggregations from the air. Marine Ecology Progress Series, 314, 159-170. http://doi.org/10.3354/meps314159

Houghton, J.D.R., Doyle, T.K., Davenport, J., Lilley, M., Wilson, R.P., \& Hays, G.C. (2007). Stranding events provide indirect insights into the seasonality and persistence of jellyfish medusa (Cnidaria Scyphozoa). Hydrobiologia, 589, 1-13. http://doi.org/10.1007/s10750-007-0572-2

Kramp, P.L. (1924). Medusae. Rep. Dan. Oceanogr. Exped. Mediterr. 2 (Biol.) (1): 1-67.

Lo Bianco, S. (1909). Notizie biologiche riguardanti specialmente il periodo di maturità sessuale degli animali del Golfo di Napoli [Biological news especially concerning the period of sexual maturity of the animals of the Gulf of Naples]. Mittheilungen Zoologischen Station Neapel, 8, 513-761.

Malej, A., \& Malej, Jr. A. (2004). Invasion of the jellyfish Pelagia noctiluca in Northern Adriatic: a non-success story. In Dumont, H., Shiganova, T., Niermann, U (Eds.), Aquatic Invasions in Black, Caspian and Mediterranean Sea. Kluwer Academic Publishers, Netherlands, pp. 273-285. https://doi.org/10.1007/1-4020-2152-6_16

Milisenda, G., Martinez-Quintana, A., Fuentes, V.L., BoschBelmar, M., Aglieri, G., Boero, F., \& Piraino, S. (2016). Reproductive and bloom patterns of Pelagia noctiluca in the Strait of Messina, Italy. Estuarine, Coastal and Shelf Science, 201, 29-39.

http://doi.org/10.1016/j.ecss.2016.01.002

Molinero, J.C., Ibanez, F., Nival, P., Buecher, E., \& Souissi, S. (2005). North Atlantic climate and northwestern Mediterranean plankton variability. Limnology Oceanography, 50, 1213-1220.

http://doi.org/10.4319/lo.2005.50.4.1213

Morand, P., Goy, J., \& Dallot, S. (1992). Recruitment and longterm fluctuations of Pelagia noctiluca (Cnidaria, Scyphozoa). Annales de l'Institut Océanographique, 68, 151-158.

Purcell, J.E., Brown, E.D., Stokesbury, K.D.E., Haldorson, L.H., \& Shirley, T.C. (2000). Aggregations of the jellyfish Aurelia labiate: abundance, distribution, association with age-0 walleye pollock, and behaviors promoting aggregation in Prince William Sound, Alaska, USA. Marine Ecology Progress Series, 195, 145-158. http://doi.org/10.3354/meps195145

Purcell, J. E., Uye, S., \& Lo, W. (2007). Anthropogenic causes of jellyfish blooms and their direct consequences for humans: a review. Marine Ecology Progress Series, 350, 153-174. http://doi.org/10.3354/meps07093

Rosa, S., Pansera, M., Granata, A., \& Guglielmo, L. (2013). Interannual variability, growth, reproduction and feeding of Pelagia noctiluca (Cnidaria: Scyphozoa) in the Straits of Messina (Central Mediterranean Sea): Linkages with temperature and diet. Journal of Marine Systems, 111-112, 97-107.

http://doi.org/10.1016/j.jmarsys.2012.10.001

Rottini-Sandrini, L., \& Avian, M. (1983). Biological cycle of Pelagia noctiluca: morphological aspects of the development from planula to ephyra. Marine Biology, 74, 169-174. http://doi.org/10.1007/bf00413920

Rottini-Sandrini, L., \& Avian, M. (1989). Feeding mechanism of Pelagia noctiluca (Scyphozoa: Semaeostomeae); laboratory and open sea observations. Marine Biology, 102, 49-55. http://doi.org/10.1007/BF00391322

Rottini-Sandrini, L., \& Avian, M. (1991). Reproduction of Pelagia noctiluca in the central and northern Adriatic Sea. Hydrobiologia, 216/217, 197-202. http://doi.org/10.1007/BF00026462

Sabatés, A., Pagès, F., Atienza, D., Fuentes, V.L., Purcell, J.E., \& Gili, J.M. (2010). Planktonic cnidarian distribution and feeding of Pelagia noctiluca in the NW Mediterranean Sea. Hydrobiologia, 645, 153-165. http://doi.org/10.1007/s10750-010-0221-z 
Spallanzani, L. (1799). Méduses phosphoriques observées dans le détroit de Messine. Voyages dans les deux Siciles et dans quelques parties des Apennins [Phosphorus jellyfish observed in the Strait of Messina. Trips in the two Sicilies and some parts of the Apennines]. Vol. 4, pp. 137-171. Paris.
Tilves, U., Purcell, J.E., Fuentes, V.L., Torrents, A., Pascual, M., Raya, V., Gilli, J.M., \& Sabatés, A. (2016). Natural diet and predation impacts of Pelagia noctiluca on fish eggs and larvae in the NW Mediterranean. Journal of Plankton Research, 38(5), 1243-1254.

http://doi.org/10.1093/plankt/fbw059 